\title{
Effects of Initial Concentration on Flocculation Size and Settling Velocity of Marine Hydraulic Fill Clay
}

\author{
Yang Shen ${ }^{1} \cdot$ Yinghao Zhu ${ }^{1} \cdot$ Dongdong Ge ${ }^{1} \cdot$ Xue Shen ${ }^{1}$
}

Published online: 14 September 2016

(C) The Author(s) 2016. This article is published with open access at Springerlink.com

\begin{abstract}
Using marine hydraulic fill clay to reclaim land is the main mean to deal with land supply and demand in coastal area. Detecting the soil's settling velocity, which is mainly affected by initial concentration of clay, is significant for filling projects. In this paper the marine clay of the East China Sea was used for tests to study the floc size and the settling velocity properties with different initial concentrations. According to SEM tests, it can be found that the typical floc size is about $17.5 \mu \mathrm{m}$ in suspensions of different initial concentrations, so by using the Stokes' formula the typical floc's theoretical velocity is calculated. Then the settling column tests were carried out, and the formation of suspension-water interface was found related to initial concentration. When the initial concentration is $120 \mathrm{~g} \mathrm{~L}^{-1}$, the interface's settling velocity is a little smaller than the theoretical value. As the initial concentration increased, the interface's settling velocity reduced at a decreasing rate. Finally a modified semi-empirical formula is established to calculate the interface's settling velocity of constant settling stage in different initial concentrations, which is significant for the study of hindered settling and the design of hydraulic fill elevation.
\end{abstract}

Keywords Settling velocity · Suspension-water interface . Floc size $\cdot$ Land reclamation

Yang Shen

shenyang1998@163.com

Yinghao Zhu

zhuyinghaolink@163.com

1 Key Laboratory of Ministry of Education for Geomechanics and Embankment Engineering, Hohai University, Nanjing 210098, China

\section{Introduction}

As the rapid development of coastal areas and the increasing population, the contradiction of land supply and demand is more and more serious. Using hydraulic fill for land reclamation is undoubtedly a fast and effective method to fill a large area of land in coastal areas. In the 17th century, Japan began to reclaim land in a large-scale. The spring up of land reclamation in China was from 1960s, before late of 20th century China had filled $12,000 \mathrm{~km}^{2}$ land, which is still increasing with about $100 \mathrm{~km}^{2}$ every year.

In the past decades the studies on the properties and behavior of sedimentation of clay-water mixtures has increased gradually, motivated by the awareness of the importance of hydraulic fill in coastal areas. As a study (Kynch 1952) shown, the formation of suspension-water interface and its settling velocity are two of the key characteristics in the study of clay-water sedimentation. In spite of the importance of the settling velocity, it is nearly impossible to obtain its actual value in situ, and in most cases it is obtained from laboratory experiments or predicted by empirical formulas.

Many researches have been carried out on the properties of cohesive sedimentation (Berres et al. 2005; Koo 2009; Winterwerp et al. 2006). The particle size and floc size distributions in clay suspensions were studied by Micheal (Micheal et al. 2012) and Iain (Iain et al. 2013). George (George et al. 2010) analyzed the size and settling velocity of suspended cohesive sediments by holography. And later the influence factors of the settling velocity of cohesive sediments were studied (Tan et al. 2012; Winkler et al. 2012). Then Malarkey (Malarkey et al. 2013) developed a simple method to determine the settling velocity distributions from settling velocity tubes (SVTs).

In contrast, few researches have been published on the properties of the formation of suspension-water interface and its settling velocity. This paper presents a study on the characteristics of 
floc size and suspension-water interface in dilute clay-water mixtures. By SEM tests, the typical floc size and its theoretical settling velocity, based on the Stokes's formula, have been measured. And then according to settling column tests the settling velocity of suspension-water interface of different initial concentrations was measured, which could reveal the effects of different initial concentrations on the settling velocity characteristics of interface. Finally a modified semi-empirical formula is established to calculate the settling velocity of suspension-water interface with different initial concentrations.

\section{Material and Methods}

\section{Basic Properties of Test Clay}

The marine clay of settling tests is from the East China Sea. And its basic property parameters and grain size distribution curve measured from laser particle size analysis are shown in Table 1 and Fig. 1. Specific gravity was measured from pycnometer method; liquid limit, plastic limit and plasticity index were determined by Standard Test Methods (ASTM D4318, 2010). The main mineral composition of the test clay estimated from X-ray diffraction analyses is kaolinite, illite and chlorite.

\section{SEM Tests for Flocculation Size}

To examine the floc size of different initial concentrations in the clay's sedimentation process, the settling column tests were set in four representative initial concentrations $\left(100 \mathrm{~g} \mathrm{~L}^{-1}, 150 \mathrm{~g} \mathrm{~L}^{-1}\right.$, $200 \mathrm{~g} \mathrm{~L}^{-1}$ and $250 \mathrm{~g} \mathrm{~L}^{-1}$ ). Each concentration set three comparison tests. The cylinder volume is $1000 \mathrm{ml}$ and inner diameter is $6.1 \mathrm{~cm}$, and the initial suspension level, namely the initial settling elevation is $33.8 \mathrm{~cm}$. The type of scanning electrochemical microscopy apparatus is SSX-550.

Every settling column test should be observed all the time until there was a clear and stable suspension-water interface appeared in the cylinder. Then a pipette was used to extract $0.5 \mathrm{ml}$ suspension underneath the interface. After sampling, the SEM test began immediately. First, the conductive double-sided adhesive tape was adhered to the stage, and the backing paper was stripped to expose its adhesive surface. Second, the suspension sample was dropped onto the tap, then the stage was heated with a heat lamp to evaporate the water in the suspension sample. Finally the sample was sprayed with gold and put under the microscope to be observed. The pictures of typical floc sizes of different initial concentrations are shown in Fig. 2 (the four

Table 1 Basic property parameters of the test clay

\begin{tabular}{llll}
\hline Specific Gravity & Liquid Limit (\%) & Plastic Limit (\%) & Plasticity Index \\
\hline 2.66 & 46.5 & 28.7 & 17.8 \\
\hline
\end{tabular}

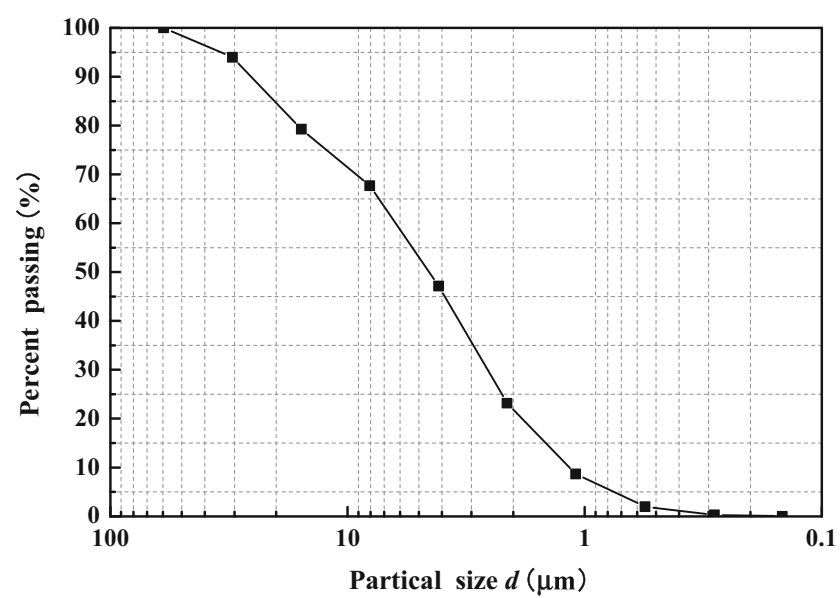

Fig. 1 Grain size distribution curve of the test clay

pictures are at different scales and magnifications, $(a)$ and $(b)$ is to show the relationships of flocs, whilst (c) and (d) is to show the single foc).

According to the results of SEM tests shown in Fig. 2, it can be found that the floc shapes are mostly block and flaky, and the flaky cohesive particles overlap with each other, and the main ways to contact are edge-to-face and edge-to-edge (Van Olphen 1977). The arrangement of particles is in a loose state so that its intergranular porosity is great. In spite of the different initial concentrations, most of the floc sizes are between 16 20 $\mu \mathrm{m}$, and the typical floc size is about $17.5 \mu \mathrm{m}$ (estimated value according to SEM tests), which can satisfactorily apply to the Stokes' formula. So if ignoring the particle-to-particle interaction in suspension, the theoretical settling velocity of typical floc, which can represent the theoretical settling velocity of the suspension-water interface, can be computed by the Stokes' formula.

The theoretical settling velocity of the typical floc based on the Stokes' formula is:

$v_{0}=\frac{\left(G_{s}-G_{w, 4}\right) \rho_{w, 4}}{1800 \times 10^{4} \eta} d_{0}^{2}$

Where $v_{0}$ is the theoretical settling velocity of typical floc; $G_{\mathrm{s}}, G_{\mathrm{w}, 4}$ are respectively corresponded to the specific gravity of solid grain and $4^{\circ}$ Celsius water; $\rho_{\mathrm{w}, 4}$ is the density of $4^{\circ}$ Celsius water, here takes $1.0 \mathrm{~g} \mathrm{~cm}^{-3} ; g$ is the acceleration of gravity, here takes $981 \mathrm{~cm} \mathrm{~s}^{-2} ; d_{0}$ is the typical floc size, here takes $17.5 \mu \mathrm{m}$; and $\eta$ is the dynamic viscosity coefficient of water, here takes $10^{-6} \mathrm{kPa} \cdot \mathrm{s}$.

Therefore the theoretical settling velocity of typical floc can be calculated by formula (1), which is: $v_{0}=0.02771 \mathrm{~cm} \mathrm{~s}^{-1}$.

\section{Settling Column Test}

This settling column tests aim at studying the effects of different initial concentrations on the properties of the settling 
Fig. 2 a The floc size of $100 \mathrm{~g} \mathrm{~L}^{-1}, \mathrm{M}=2.50 \mathrm{k} ; \mathbf{b}$ The floc size of $150 \mathrm{~g} \mathrm{~L}^{-1}, \mathrm{M}=2.00 \mathrm{k}$; The floc size of $200 \mathrm{~g} \mathrm{~L}^{-1}, \mathrm{M}=$ $4.50 \mathrm{k}$; $\mathbf{d}$ The floc size of $250 \mathrm{~g} \mathrm{~L}^{-1}, \mathrm{M}=4.00 \mathrm{k}(\mathrm{M}=$ magnification)

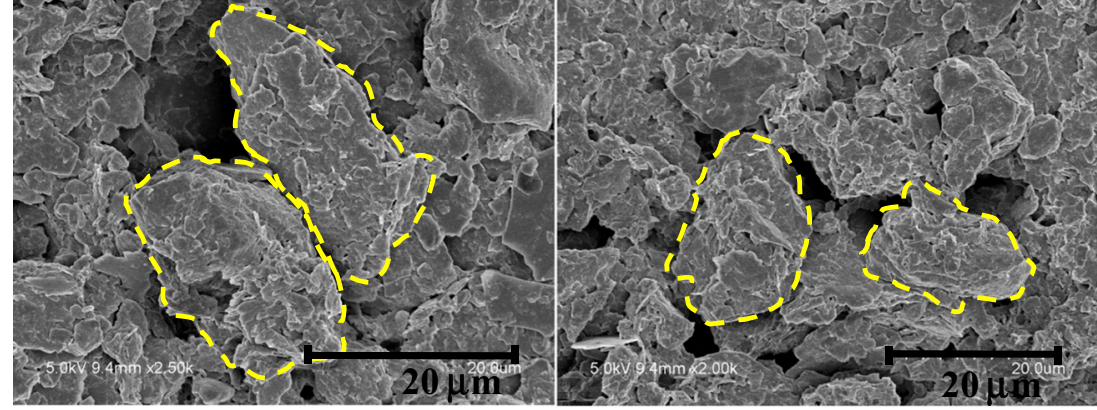

(a)

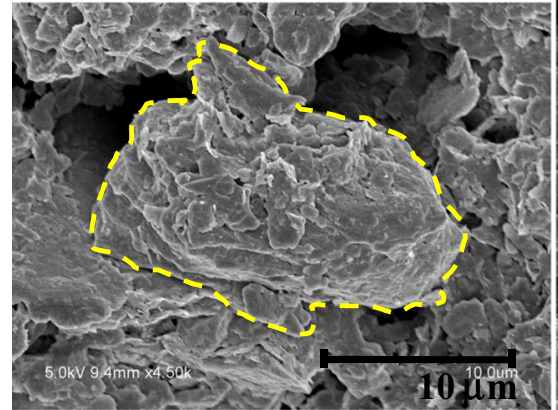

(c) (b)

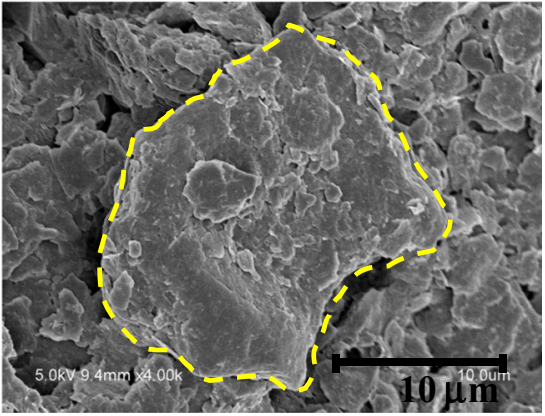

(d) velocity of suspension-water interface. Because the general initial concentration of reclamation projects is about $200 \mathrm{~g} \mathrm{~L}^{-1}$, and in order to better study the effects of different initial concentrations, the initial concentrations of the test are set at: $100 \mathrm{~g} \mathrm{~L}^{-1}, 120 \mathrm{~g} \mathrm{~L}^{-1}, 150 \mathrm{~g} \mathrm{~L}^{-1}, 180 \mathrm{~g} \mathrm{~L}^{-1}, 200 \mathrm{~g} \mathrm{~L}^{-1}$, $220 \mathrm{~g} \mathrm{~L}^{-1}, 250 \mathrm{~g} \mathrm{~L}^{-1}, 300 \mathrm{~g} \mathrm{~L}^{-1}$ and $320 \mathrm{~g} \mathrm{~L}^{-1}$. In the settling process, the characteristics of the formation of suspensionwater interface and its settling velocity can be obtained by three curves: the interface elevation's variation with time, the interface velocity's variation with time and the interface velocity's variation with initial concentration.

\section{Results and Discussion}

According to the results of the settling column tests, three curves can be directly drawn. The curve of the interface elevation's variation with time can be used to interpret the effects of different initial concentrations on the formation of the suspension-water interface, while the other two curves can be applied for revealing the properties of the settling velocity of the interface in different initial concentrations. Finally the relationship of the settling velocity of interface and initial concentration is able to be fitted to a line in a double logarithmic, and combined with the theoretical settling velocity calculated by formula (1), a modified semi-empirical formula can be established to calculate the settling velocity of suspension-water interface in different initial concentrations.

\section{Effects of Initial Concentration on the Formation of Suspension-Water Interface}

As a result, the relationship between the interface elevation and time is shown in Fig. 3.

From the test results in Fig. 3, it is known that the formation of suspension-water interface is not inevitable, but closely related to initial concentration. Only when the initial concentration changes between 100 to $300 \mathrm{~g} \mathrm{~L}^{-1}$ can the mixture forms a clear and distinguishable suspension-water interface. When initial concentration is $150 \sim 300 \mathrm{~g} \mathrm{~L}^{-1}$, a clear interface is formed at the beginning of the sedimentation. While initial concentration is $120 \sim 150 \mathrm{~g} \mathrm{~L}^{-1}$, the interface formed a little

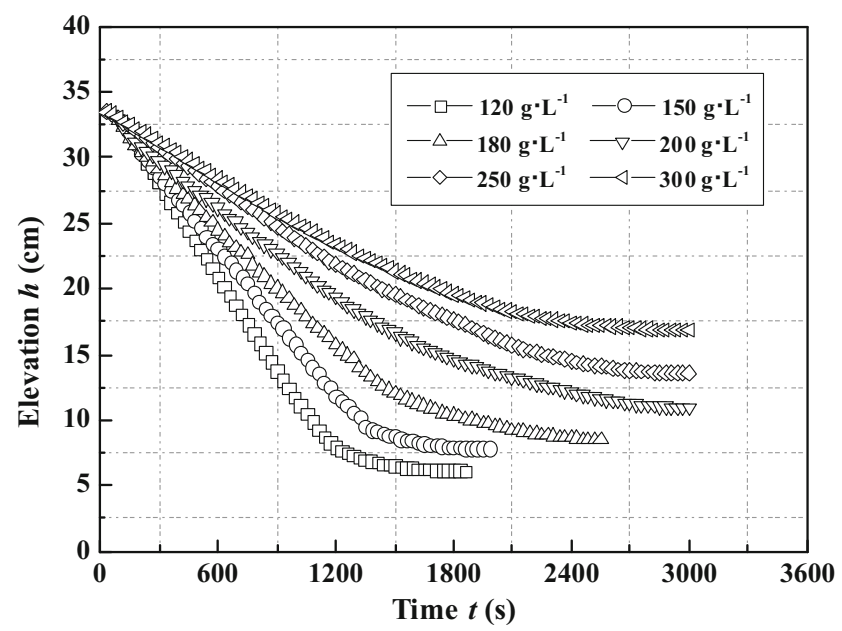

Fig. 3 Interface elevation's variation with time 
lower and later than higher concentrations. The lower of the initial concentration the lower of the elevation of the interface formed, but if the initial concentration is less than $100 \mathrm{~g} \mathrm{~L}^{-1}$ or greater than $300 \mathrm{~g} \mathrm{~L}^{-1}$, there would be no apparent suspension-water interface observed.

The reason of this phenomenon is that as the initial concentration is very low, the spacing between the particles is relatively large at the beginning of the sedimentation so that the primary flocs have a little chance to interact with each other and they also can not effectively connect and overlap to form larger flocs. So this phase performs as dispersed sedimentation. As the settling goes on, the concentration of the suspension is increased and the primary flocs begin to connect, then the interface appears. When the initial concentration is lower than $100 \mathrm{~g} \mathrm{~L}^{-1}$, the flocculation is too weak to be observed. When the initial concentration is higher than $300 \mathrm{~g} \mathrm{~L}^{-1}$, the particles are able to transmit force between each other, the settling process accesses to self-weight consolidation phase, so interface cannot be observed.

\section{Effects of Initial Concentration on Settling Velocity Properties of Suspension-Water Interface}

The interface settling velocity's variation with time in different initial concentrations is shown in Fig. 4.

As is shown in Fig. 4, the settling process of different initial concentrations can probably be divided into three stages: constant settling stage; transitional stage; self-weight consolidation stage. The constant settling stage probably completes before $1200 \mathrm{~s}$, while the self-weight consolidation stage probably begins at $1500 \mathrm{~s}$, and the middle stage is a transition process from constant settling stage to self-weight consolidation stage. The time to complete the constant settling stage of different initial concentrations is almost the same, but the interface settling velocities of this stage are different. It indicates that the initial concentration affects the interface settling velocity of the constant settling stage, but has little influence on

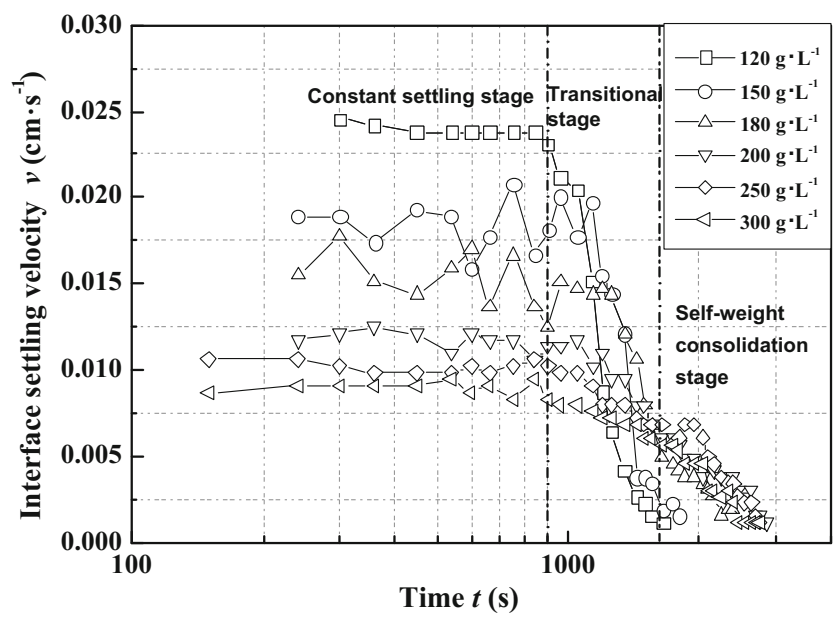

Fig. 4 The interface settling velocity's variation with time the time to complete this stage. In addition, as the initial concentration increased the transitional process becomes less and less apparent.

Considering practical hydraulic fill projects, the settling velocity of constant settling stage seems to be more important. The relationship between that velocity and the initial concentration is shown in Fig. 5.

The theoretical settling velocity calculated by the Stokes' formula is: $v_{0}=0.02771 \mathrm{~cm} \mathrm{~s}^{-1}$. As is shown in Fig. 5, when the initial concentration is $120 \mathrm{~g} \mathrm{~L}^{-1}$, the actually measured settling velocity compared to the theoretical value is a little small. As the initial concentration increased, the settling velocity of constant settling stage is gradually reduced at a decreasing rate. This variation property is able to be appropriately illustrated by the interaction of flocs. When the initial concentration is very low, there is nearly no interaction between flocs, so the flocs settle only by self-weight and their settling velocities are almost the same to the theoretical one. As the initial concentration increased, the interaction of flocs becomes more and more stronger, which can apparently slow down the flocs' settling velocities. But that reduce effect will be weaken as the increasing of the initial concentration.

\section{A Modified Semi-Empirical Formula for Settling Velocity of Suspension-Water Interface}

When the relationship shown in Fig. 5 is described in a double logarithmic coordinate, it is found that the settling velocity has a significant linear relationship with the initial concentration. So the adoption of a linear fit to approximately depict that relationship is appropriate. The relationship is figured in Fig. 6 and the expression is shown below:

$\lg v=-1.19 \lg c+0.85$

Where $c$ is the initial concentration and $v$ is the settling velocity of suspension-water interface in the constant settling

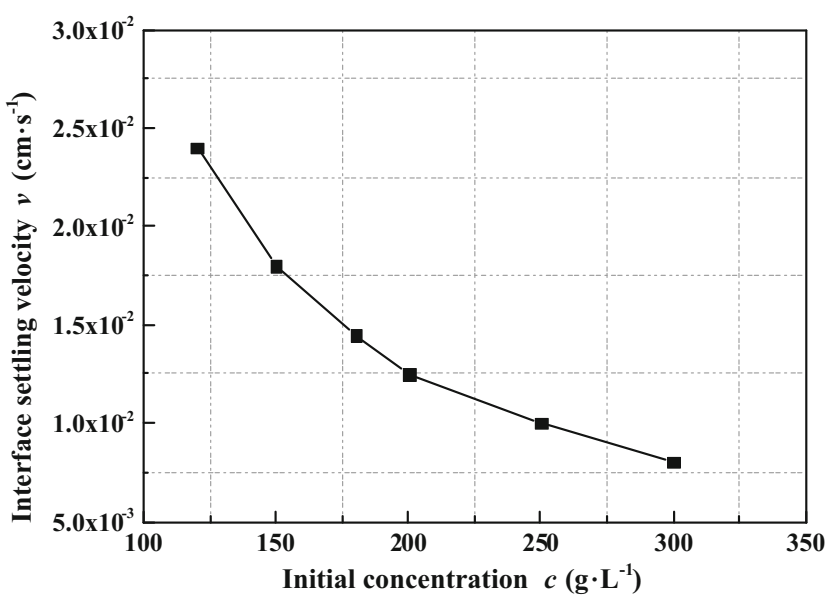

Fig. 5 The interface settling velocity's variation with initial concentration 


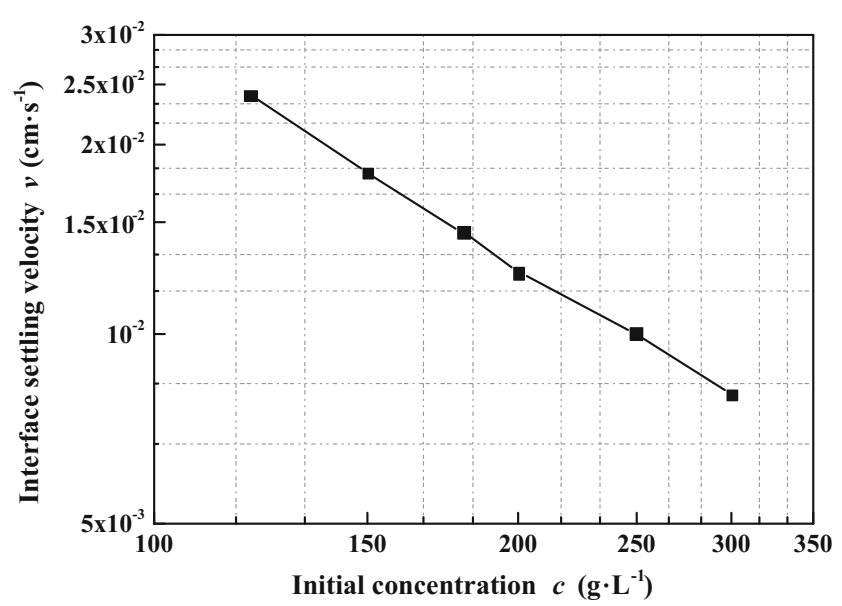

Fig. 6 The interface settling velocity's variation with initial concentration in a double logarithmic coordinate

stage. The correlation coefficient of the expression is: $R^{2}=$ 0.998 , which means the expression is able to depict the relationship in a very appropriate way.

If the theoretical settling velocity $v_{0}$ calculated from Eq. (1) can be substituted into Eq. (2), and assuming that $v_{0}$ corresponds with the initial concentration $c_{0}$, then:

$\lg v_{0}=-1.19 \lg c_{0}+0.85$

The $c_{0}$ calculated from Eq. (3) is $105.4 \mathrm{~g} \mathrm{~L}^{-1}$, which indicates that when the initial concentration is less than $105.4 \mathrm{~g} \mathrm{~L}^{-1}$, the interaction of flocs in constant settling stage is so weak that it can be ignored, thus the sedimentation of this stage can be treated as dispersion settling.

Using Eq. (2) to minus Eq. (3):

$v=v_{0}\left(\frac{c}{c_{0}}\right)^{-1.19}$

Equation (4) is a modified semi-empirical formula to calculate the interface settling velocity of constant settling stage with different initial concentrations. The accuracy of the formula relies on the accurate measurement of typical floc size and the precise calculation of theoretical settling velocity of typical floc. Because of the precision of SEM and the widespread acceptance of the Stokes's formula, the interface settling velocity of constant settling stage can be appropriately calculated by that formula. It is significant for the study of the whole hindered settling process and the design of hydraulic fill elevation.

\section{Conclusions}

The marine hydraulic fill of the East China Sea has been tested. According to SEM tests, the typical floc size was found and its theoretical settling velocity was calculated by the Stokes' formula. Then the interface settling velocities were obtained by settling column tests. With the analysis of the interface settling velocity's variation with time in different initial concentrations, the properties of the interface settling velocity affected by initial concentration are found. Finally with the use of linear fitting, the relationship between interface settling velocity of constant settling stage and initial concentration can be depicted by a modified semi-empirical formula. The detailed conclusions can be summarized in four points.

(1) According to the results of SEM test, it can be found that with different initial concentrations most of the floc sizes are able to remain at $16 \sim 20 \mu \mathrm{m}$, and the typical floc size is about $17.5 \mu \mathrm{m}$ (estimated value according to SEM tests), So if ignoring particle-to-particle interaction in the suspensions, the theoretical settling velocity of typical floc can be computed by the Stokes' formula, which is: $v_{0}=0.02771 \mathrm{~cm} \mathrm{~s}^{-1}$.

(2) In the settling process of the tests, only when the initial concentration changes from 100 to $300 \mathrm{~g} \mathrm{~L}^{-1}$ can the mixture forms a clear and distinguishable suspension-water interface, meanwhile the initial concentration makes an effect on the interface settling velocity of constant settling stage, but it has little influence on the time to complete this stage.

(3) When the initial concentration is $120 \mathrm{~g} \mathrm{~L}^{-1}$, the actually measured settling velocity compared to the theoretical value is lesser than the theoretical expected value. As initial concentration increased, the settling velocity of constant settling stage is gradually reduced at a decreasing rate.

(4) Combining the theoretical settling velocity calculated by the Stokes' formula and the actually measured settling velocity by the settling column test, a modified semiempirical formula is established to calculate the interface settling velocity of constant settling stage in different initial concentrations, which is significant for the study of hindered settling and the design of hydraulic fill elevation.

Acknowledgments The authors acknowledge the financial support of the National Natural Science Foundation of China (51479060) and the Fundamental Research Funds for the Central Universities (2015B17114).

Open Access This article is distributed under the terms of the Creative Commons Attribution 4.0 International License (http:// creativecommons.org/licenses/by/4.0/), which permits unrestricted use, distribution, and reproduction in any medium, provided you give appropriate credit to the original author(s) and the source, provide a link to the Creative Commons license, and indicate if changes were made.

\section{References}

Berres S, Bürger R, Tory EM (2005) Applications of polydisperse sedimentation models. Chem Eng J 111:105-117 
George WG, AM W, Nimmo S (2010) The application of holography to the analysis of size and settling velocity of suspended cohesive sediments. Limnol Oceanogr Methods 8:1-15

Iain TM, Christopher EV, Peter DT, Benjamin DM (2013) Acoustic scattering from a suspension of flocculated sediments. J Geophys Res: Oceans 118:2581-2594

Koo S (2009) Estimation of hindered settling velocity of suspensions. J Ind Eng Chem 15:45-49

Kynch GJ (1952) A theory of sedimentation. Trans Faraday Soc 48:166-176

Malarkey J, Jago CF, Hübner R, Jones SE (2013) A simple method to determine the settling velocity distribution from settling velocity tubes. Cont Shelf Res 56:82-89

Micheal F, Matthias B, Byung JL, Peihung C, Jason CS (2012) Hydrometeorological influences and multimodal suspended particle size distributions in the Belgian nearshore area (southern North Sea). Geo-Mar Lett 32:123-137

Standard ASTM (2010). D4318 (2010) Standard Test Methods for Liquid Limit, Plastic Limit, and Plasticity Index of Soils, ASTM International

Tan XL, Zhang GP, Yin H, Reed AH, Furukawa Y (2012) Characterization of particle size and settling velocity of cohesive sediments affected by a neutral exopolymer. Int J Sediment Res 27:473-485

Van Olphen H (1977). An introduction to clay colloid chemistry, Wiley Winkler MK, Bassin JP, Kleerebezem R, Lans RGJM, Loosdrecht MCM (2012) Temperature and salt effects on settling velocity in granular sludge technology. Water Res 46:5445-5451

Winterwerp JC, Manning AG, Martens C, Mulder T, Vanlede J (2006) A heuristic formula for turbulence-induced flocculation of cohesive sediment. Estuar Coast Shelf Sci 68:195-207 